\title{
Inalação da fumaça do tabaco provoca alterações histopatológicas no nervo olfatório de ratas
}

\author{
Inhalation of tobacco smoke causes histopathological changes \\ in the olfactory nerve of rats

\begin{abstract}
Flávio José Pereira de Almeida Ferreira ${ }^{1^{*}}$, Rodrigo César Rosa ${ }^{2}$, Ana Paula Espíndula ${ }^{3}$, Vandair Gonçalves Pereira ${ }^{4}$, Sanívia Aparecida de Lima Pereira ${ }^{5}$, Fabrizio Antonio Gomide Cardoso ${ }^{6}$
\end{abstract}

\begin{abstract}
${ }^{1}$ Fisioterapeuta, Acadêmico do Programa de Pós-graduação em Ciências da Saúde da Universidade Federal do Triângulo Mineiro, MG; ${ }^{2}$ Professor Doutor de Anatomia Humana da Universidade Federal do Triângulo Mineiro, MG; ${ }^{3}$ Professora Pós-doutora do Programa de Pós-graduação em Ciências da Saúde da Universidade Federal do Federal do Triângulo Mineiro, MH; ${ }^{5}$ Professora Doutora do Programa de Pós-graduação em Ciências da Saúde da Federal do Triângulo Mineiro, MG
\end{abstract} \\ Triângulo Mineiro, MG; ${ }^{4}$ Bióloga, Mestranda do Programa de Pós-graduação em Ciências da Saúde da Universidade \\ Universidade Federal do Triângulo Mineiro, MG; ${ }^{6}$ Professor Doutor Associado de Anatomia Humana da Universidade
}

\begin{abstract}
Resumo
Introdução: o tabagismo é uma das principais causas evitáveis de mortes no mundo representando um problema de saúde pública. Objetivo: investigar a relação da exposição passiva à fumaça principal do cigarro e as possíveis alterações histomorfométricas das células gliais, arteríolas e da matriz extracelular do nervo olfatório de ratas. Metodologia: trata-se de um estudo experimental, analítico e quantitativo. Vinte ratas randomizadas divididas em dois grupos, controle e tabaco, foram expostas à inalação da fumaça principal do cigarro por 60 dias utilizando dispositivo validado na literatura. Resultados: a exposição à inalação da fumaça principal do cigarro resultou em alterações significativas no grupo tabaco, tais como, elevação nos níveis de cotinina no plasma sanguíneo, aumento na espessura da parede dos vasos sanguíneos, aumento na porcentagem do colágeno total do tecido, diminuição no número total de astrócitos e aumento no número total de micróglias. Conclusão: a exposição à fumaça principal do cigarro resulta em alterações histomorfométricas que poderiam causar alterações funcionais no nervo olfatório como perda sensorial olfativa. Os achados constatados são fortes o suficiente para servir como alerta a toda a população e às autoridades de saúde, no que se refere às leis antifumo, principalmente em ambientes fechados.
\end{abstract}

Palavras-chave: Anatomia. Colágeno. Nervo. Olfatório. Neuroglia. Produtos do Tabaco.

\begin{abstract}
Introduction: smoking is one of the main preventable causes of death in the world and represents a worldwide public health problem. Objective: to investigate the relationship of second hand tobacco smoke and possible histomorphometric changes of glial cells, arterioles and extracellular matrix of the olfactory nerve in rats. Methodology: experimental, analytical and quantitative study, twenty wistar animals randomized into two control and tobacco groups, were exposed to inhalation of main cigarette smoke for 60 days using a device validated in the literature. Results: exposure to inhalation of main cigarette smoke resulted in changes in the tobacco group, such as increased levels of cotinine in the blood plasma, increased thickness of the blood vessel wall, increased percentage of total tissue collagen, decreased in the total number of astrocytes and increase in the total number of microglia. Conclusion: exposure to main cigarette smoke results in histomorphometric changes that can cause changes in the olfactory nerve such as sensory olfactory loss. Our findings are strong enough to serve as a warning to the entire population and to health authorities in relation to smokefree laws especially in closed environments.

Keywords: Anatomy. Collagen. Neuroglia. Olfactory Nerve. Tobacco Products.
\end{abstract}

\section{INTRODUÇÃO}

O tabagismo é uma das principais causas evitáveis de mortes no mundo representando um problema de saúde pública que leva a população a óbito e onera a sociedade. Dados da Organização mundial da Saúde (OMS, 2017) ressalta que globalmente mais de 8 milhões de pessoas

Correspondente/Corresponding: *Flávio José Pereira de Almeida Ferreira - End: Rua Ana Modesto Ferreira n139 parque do mirante Uberaba MG. - Tel: (34) 33219134 / 98822-9177-E-mail:flavio-4040@ hotmail.com morrem a cada ano como resultado do tabagismo, mais de 7 milhões dessas mortes são resultado do uso direto do tabaco, enquanto cerca de 1,2 milhão são resultado de não fumantes expostos ao fumo passivo.

O controle do tabaco não é fácil enfrenta um inimigo aterrorizante representado por uma indústria do tabaco enorme, seu alvo é especificamente às mulheres e os jovens adultos e se utiliza de um Marketing que basicamente cria a demanda inventando motivos pelos quais uma pessoa deveria fumar, essa lança novos produtos como os cigarros de tabaco para aquecimento e 
não queima que produzem emissões convencionais e secundárias de produtos químicos prejudiciais (FRIED; GARDNER, 2020). A fumaça dos cigarros tradicionais contém milhares de substâncias químicas, sendo constituída por fumaça principal, produzida em alta temperatura, e periférica, produzida em baixa temperatura, decorrente da queima lenta e espontânea do cigarro (MELLO; OKAY; BOTELHO, 2007).

Durante a pandemia da doença coronavírus (COVID-19) a questão do tabagismo e o risco de infecção respiratória aguda são novamente tópicos, o foco na prevenção e cessação do tabagismo concentra-se nas mortes não infecciosas. Fumantes parecem ser mais vulneráveis à infecção pelo novo coronavírus, fumar é prejudicial para o sistema imunológico e sua capacidade de resposta a infecções, tornando os fumantes mais vulneráveis as doenças infecciosas. Fumar qualquer tipo de tabaco tradicional ou eletrônico reduz a capacidade pulmonar e aumenta o risco de muitas infecções respiratórias e pode aumentar a gravidade da covid 19 (VARDAVAS; NIKITARA, 2020).

O circuito do sistema olfativo dos mamíferos tem início com os neurônios sensoriais olfativos no neuroeptélio olfativo, uma estrutura que se desenvolve a partir da placa olfativa, os axônios formam o nervo olfatório que se projeta para o bulbo olfatório e invagina-se no telencéfalo estabelecendo sinapses com os dendritos apicais das células mitrais dando origem aos glomérulos do bulbo olfatório (DE CASTRO, 2009). O sistema nervoso central possui grande quantidade de células da neuroglia, dentre elas, astrócitos, micróglias e os oligodendrócitos, essas essenciais para a manutenção e funcionamento do sistema nervoso central.

A literatura aborda claramente a ação deletéria da fumaça do tabaco sobre o epitélio e mucosa olfatória de ratos, levando a alterações degenerativas tóxicas (SAHIN; ORTUG; ORTUG, 2018) mas não há relatos na literatura de análise histomorfométrica no nervo olfatório de ratas expostas a fumaça principal do cigarro. Em vista da necessidade de padronização experimental, deve-se salientar a importância em trabalhar com modelos animais que se aproximam do padrão humano, para maior entendimento sobre os efeitos provocados pela inalação da fumaça do tabaco, uma vez que seu uso acarreta inúmeros problemas de saúde. Neste contexto, surge a hipótese desse estudo, a inalação da fumaça principal do cigarro provoca alterações histopatológicas no nervo olfatório de ratas. Contudo, sabendo da importância do nervo olfatório para condução dos impulsos sensoriais e das ações deletérias sistêmicas dos componentes do cigarro, justifica-se a realização do presente estudo experimental, o qual teve o objetivo de investigar a relação da exposição passiva à fumaça principal do cigarro e as possíveis alterações histomorfométricas das células gliais, arteríolas e da matriz extracelular do nervo olfatório de ratas.

\section{METODOLOGIA}

Estudo experimental, analítico e quantitativo, aprovado pelo Comitê de Ética no Uso de Animais (CEUA) da Universidade Federal do Triângulo Mineiro (UFTM) sob número de protocolo 414/2017. No estudo foram utilizadas vinte ratas, Wistar da linhagem albina, com oito semanas de idade e massa corpórea inicial de $200 \mathrm{~g}( \pm 10 \mathrm{~g})$, foram alojadas em gaiolas padrão no biotério setorial da Disciplina de Anatomia Humana da UFTM. Os animais foram agrupados aleatoriamente nos grupos: Grupo Controle, $\mathrm{GC}(\mathrm{n}=10)$ formado por animais não expostos à fumaça principal do cigarro, GT ( $n=10)$ Grupo formado por animais expostos à fumaça principal do cigarro. $O$ período experimental teve duração de 60 dias.

Os animais foram mantidos em temperatura ambiente de 20 a $24^{\circ} \mathrm{C}$, com controle de luminosidade (claro/ escuro: 12 / 12 horas) e umidade relativa do ar em 55\% $( \pm 10 \%)$, recebendo ração para roedores (Nuvilab ${ }^{\circledR}$ CR-1Quimtia) e água ad libitum. Os animais foram expostos à fumaça do cigarro, por meio de um dispositivo específico, confeccionado de acordo com o design e metodologia validada na literatura (GENTNER; WEBER, 2012). Durante a queima do cigarro uma bomba peristáltica (Provitec AWG 5.000 AXD, São Paulo, SP, Brasil) aspirou a fumaça com $80 \%$ da vazão máxima (0,9 L / min), transferindo-a para uma câmara de distribuição e depois para os compartimentos cilíndricos, de acondicionamento dos animais. O equipamento possuía temporizador, utilizado para controlar a INTRODUÇÃO de fumaça do cigarro por 15 segundos (s) e sua substituição por ar ambiente por 30 s, completando um ciclo de 45 s. Após a exposição o excesso de fumaça era aspirado para o exterior através de um exaustor acoplado.

Os animais passaram pelo período de ambientação durante uma semana, sendo colocados nas condições de exposição, sem a queima de cigarros. Na segunda semana, teve início ao período de adaptação, em que os animais foram expostos à fumaça de um cigarro pela manhã e um no período da tarde. Na sequência, teve início ao período experimental, em que os animais foram expostos à fumaça de dois cigarros consecutivos pela manhã e dois cigarros consecutivos à tarde, com intervalo de seis horas entre as exposições, durante 60 dias. 0 tempo de exposição diária foi de 40 minutos (min.) sendo duas exposições de 20 min ao dia, perfazendo um total de $2400 \mathrm{~s}$. Com base no tempo total de um ciclo (45s), pode-se determinar o total de ciclos expositivos diários, que é de aproximadamente 53. Portanto, levando em consideração que o tempo de exposição à fumaça em cada ciclo é de 15s, cada animal foi exposto à 795s, ou seja, 13,25 min. de exposição diária à fumaça do cigarro. Com base na vazão da bomba (0,9 Litros/min) e o tempo de exposição diária de cada animal à fumaça do cigarro $(13,25 \mathrm{~min})$, estima-se que as ratas foram expostas à aproximadamente 12 litros de fumaça por dia.

A cada sete dias, a porcentagem de monóxido de 
carbono em cada câmara cilíndrica foi aferida, utilizando um medidor portátil de monóxido de carbono (Instrupemp, ITMCO-1500, São Paulo, SP, Brasil). As quatro câmaras apresentaram níveis semelhantes de monóxido de carbono a cada ciclo $(338,79 \pm 1,16 \mathrm{mg} / \mathrm{L})$. A fonte da fumaça foi produzida pela queima de cigarros Marlboro (Phillips Morris, Santa Cruz do Sul, RS, Brasil). De acordo com as informações do fabricante no rótulo do produto, os cigarros apresentaram as seguintes concentrações: $0,8 \mathrm{mg}$ de nicotina, $10 \mathrm{mg}$ de alcatrão e $10 \mathrm{mg}$ de monóxido de carbono.

Ao final do experimento, os animais foram eutanásiados com dose excessiva de Tiopental (tiopentato de sódio) via intraperitoneal, com a coleta do plasma para dosagem da cotinina e ressecção bilateral dos nervos olfatórios. Na sequência, os nervos olfatórios foram fixados em solução de formaldeído a $10 \%$, passando por protocolo de desidratação em álcoois etílico, em concentrações crescentes (70-100\%). Posteriormente, foram diafanizados em xilol e emblocados em parafina, com realização de cortes seriados com $4 \mu \mathrm{m}$ de espessura e coloração com Hematoxilina eosina (HE) e Picrosírius (PS). As lâminas coradas pela HE foram utilizadas para a avaliação quantitativa dos oligodendrócitos, astrócitos e micróglias, além da espessura da parede das arteríolas.

As análises histomorfométricas foram realizadas com uso microscópio de luz, acoplado à sistema ZEISS/ ZEN PRIMOSTARS ${ }^{\circledR}$ (Axiocam 105 color $^{\circledR}$ ). 0 colágeno total foi avaliado por meio de lâminas coradas pelo PS, sob luz polarizada, com aumento de $400 x$, utilizando câmera de vídeo acoplada a microscópio com sistema automatizado. Assim, a presença do colágeno foi identificada por seu aspecto birrefringente, com cor avermelhada, em que o mesmo observador quantificou o percentual de colágeno total, por meio da marcação da área de todos os campos birrefringentes. A dosagem de cotinina plasmática foi realizada para avaliar os níveis de exposições e garantir a eficácia do modelo de exposição à fumaça do cigarro. Assim, foi realizada análises de cromatografia gasosa, de acordo com a metodologia de rotina do Laboratório de Análises Toxicológicas Forenses da Faculdade de Filosofia, Ciências e Letras de Ribeirão Preto (FFCLRP/USP) Padrão: cotinina em solução de 1.0 $\mathrm{mg} / \mathrm{mL}$ em metanol (Sigma-AldrichTM - Missouri, EUA) Especificidade: 97,4\%, sensibilidade-96,3\%.

A análise estatística dos dados foi realizada por meio do programa GraphPad Prism ${ }^{\circledR}$, versão 5.0. A normalidade dos dados foi verificada utilizando o teste de Shapiro Wilk, na sequência realizado o teste de Mann-Whitney e o teste de Tukey. O nível de significância adotado foi menor que $5 \%(p<0,05)$.

\section{RESULTADOS}

A exposição à inalação da fumaça principal do cigarro foi capaz de propiciar significativas alterações no nervo olfatório das ratas do grupo tabaco (GT) em comparação aos do grupo controle (GC). A tabela 1 apresentam os achados dos níveis de cotinina plasmática, espessura da parede das arteríolas e a porcentagem de colágeno. Os níveis de cotinina plasmática sofreram elevação nos animais do GT em comparação ao GC $(p<0,001)$. Com relação a espessura da parede das arteríolas e do colágeno total houve aumento significativo no GT em comparação ao $\mathrm{GC}(p<0,001)$.

Tabela 1 - Resultados da espessura da parede das arteríolas, colágeno total e níveis de cotinina do nervo olfatório.

\begin{tabular}{l|l|l}
\hline & $\mathrm{GC}$ & $\mathrm{GT}$ \\
\hline $\begin{array}{l}\text { Níveis de } \\
\text { cotinina (ng/ } \\
\mathrm{mL})\end{array}$ & $\begin{array}{l}\bar{x} \pm \text { e.p }-\mathrm{ng} / \mathrm{mL} \\
0,006 \pm 0,007\end{array}$ & $\begin{array}{l}\bar{x} \pm \text { e.p }-\mathrm{ng} / \mathrm{mL} \\
* 13,1 \pm 1,2\end{array}$ \\
\hline $\begin{array}{l}\text { Espessura da } \\
\text { parede das } \\
\text { arteríolas }\end{array}$ & $\begin{array}{l}\text { Mediana-(max-min) } \mu \mathrm{m} \\
13.816(21.413-10.618)\end{array}$ & $\begin{array}{l}\text { Mediana-(max-min) } \mu \mathrm{m} \\
\text { 27.517 (41.474-14.153) }\end{array}$ \\
\hline $\begin{array}{l}\text { Porcentagem } \\
\text { de colágeno } \\
\text { total }\end{array}$ & $\begin{array}{l}\text { Mediana-(max-min) \% } \\
3,814(7.035-1.191)\end{array}$ & $\begin{array}{l}\text { Mediana-(max-min) \% } \\
* 11.463(16.752-4.810)\end{array}$ \\
\hline
\end{tabular}

Tabela 1-Apresenta os resultados da espessura da parede das arteríolas, colágeno total e níveis de cotinina do nervo olfatório. o aumento nos níveis de cotinina plasmática nos animais do GT, aumento na espessura da parede das arteríolas do grupo GT e aumento do colágeno total em comparação com o GC.

$G C=$ Grupo controle; GT=Grupo tabaco. *Indica diferença significativa $\operatorname{com}(p<0,001)$.

Fonte: Autoria própria

A análise das células gliais (tabela 2, figura 2), demonstrou aumento de astrócitos e diminuição de micróglias no GT $(p<0,001)$. Não houve alterações significativas no número de oligodendrócitos do GT e $G C(p=0,969)$.

Tabela 2 - Comparação dos grupos controle e tabaco de astrócitos, micróglias e oligodendrócitos dos nervos olfatórios.

\begin{tabular}{|c|c|c|c|}
\hline Grupo & Células & $\begin{array}{l}\text { № de Células } \\
\text { Mediana-(max-min) }\end{array}$ & Valor de $p$ \\
\hline $\begin{array}{l}\mathrm{GC} \\
\mathrm{GT}\end{array}$ & $\begin{array}{l}\text { Astrócitos } \\
\text { Astrócitos }\end{array}$ & $\begin{array}{l}35.000-(48.000-23.000) \\
20.000-(35.000-12.000)\end{array}$ & $<0,001$ \\
\hline $\begin{array}{l}\text { GC } \\
\text { GT }\end{array}$ & $\begin{array}{l}\text { Micróglias } \\
\text { Micróglias }\end{array}$ & $\begin{array}{l}16.000-(24.000-11,000) \\
43.000-(61.000-30.000)\end{array}$ & $<0,001$ \\
\hline $\begin{array}{l}\text { GC } \\
\text { GT }\end{array}$ & $\begin{array}{l}\text { Oligodendrócitos } \\
\text { Oligodendrócitos }\end{array}$ & $\begin{array}{l}4.000-(7.000-2.000) \\
4.000-(7.0000-2.000)\end{array}$ & 0,969 \\
\hline
\end{tabular}

Tabela 2 - Apresenta a comparação dos grupos controle e tabaco de astrócitos, micróglias e oligodendrócitos dos nervos olfatórios. Podemos observar a diminuição do número de astrócitos no GT em comparação com o número de astrócitos do GC, o aumento da população de micróglias do grupo GT em comparação com a população de micróglias do grupo GC e não apresenta diferença estatística entre os grupos de oligodendrócitos. Teste estatístico Mann-Whitney. GC=Grupo controle, GT=Grupo tabaco.

Fonte: Autoria própria 
Figura 1 - Mostra o aumento do colágeno total do nervo olfatório no grupo tabaco em comparação ao grupo controle em lâminas analisadas em microscopia de luz polarizada, aumento total 800x. GC=Grupo controle, GT=Grupo tabaco.
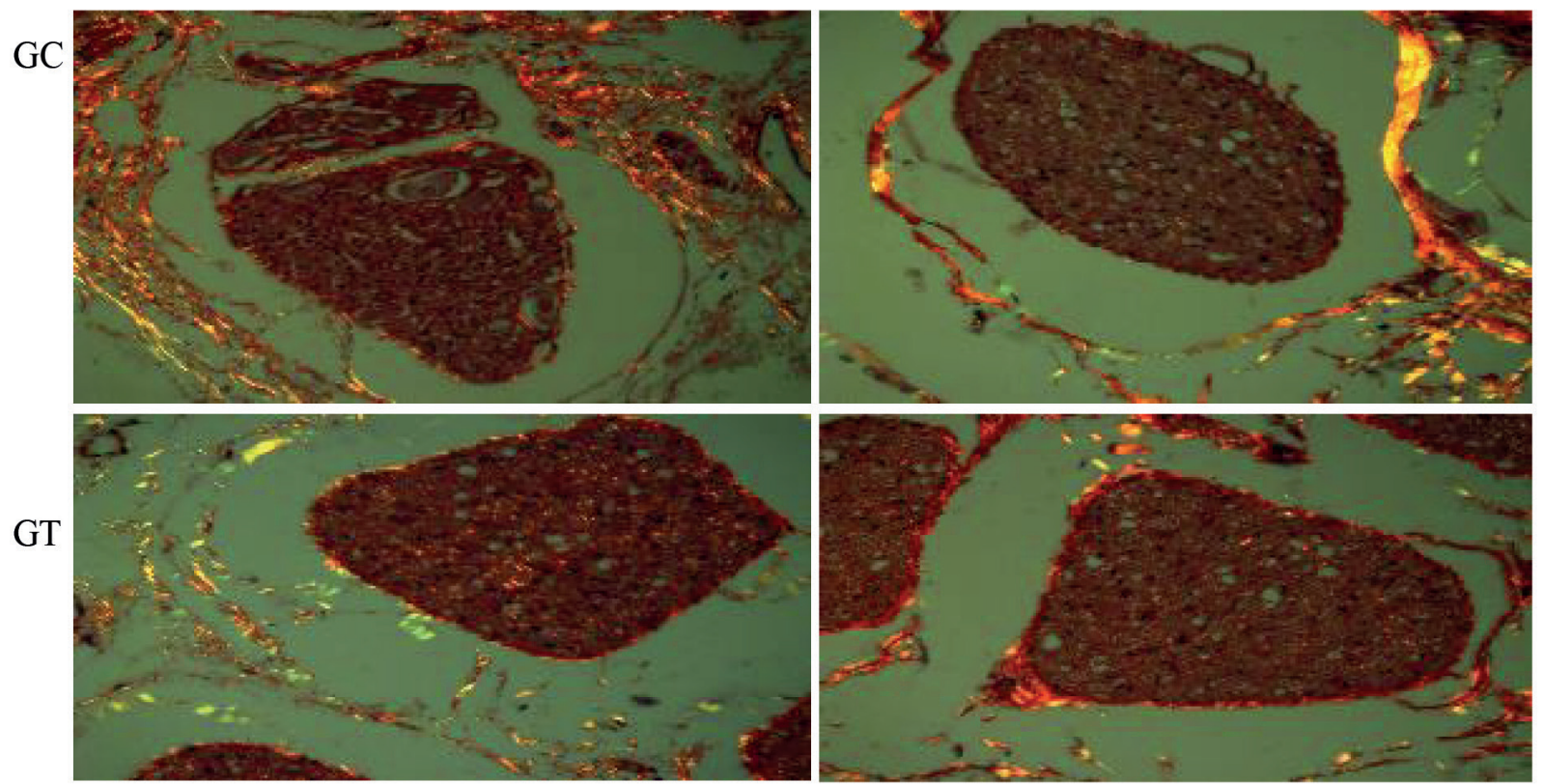

Fonte: Autoria própria

Figura 2 - Mostra células gliais (astrócitos e micróglias) no nervo olfatório dos grupos controle e tabaco, observamos diminuição na quantidade de astrócitos e aumento de micróglias no grupo tabaco GT. Coloração Hematoxilina e Eosina. Aumento total 800x. $G C=$ Grupo controle, GT=Grupo tabaco
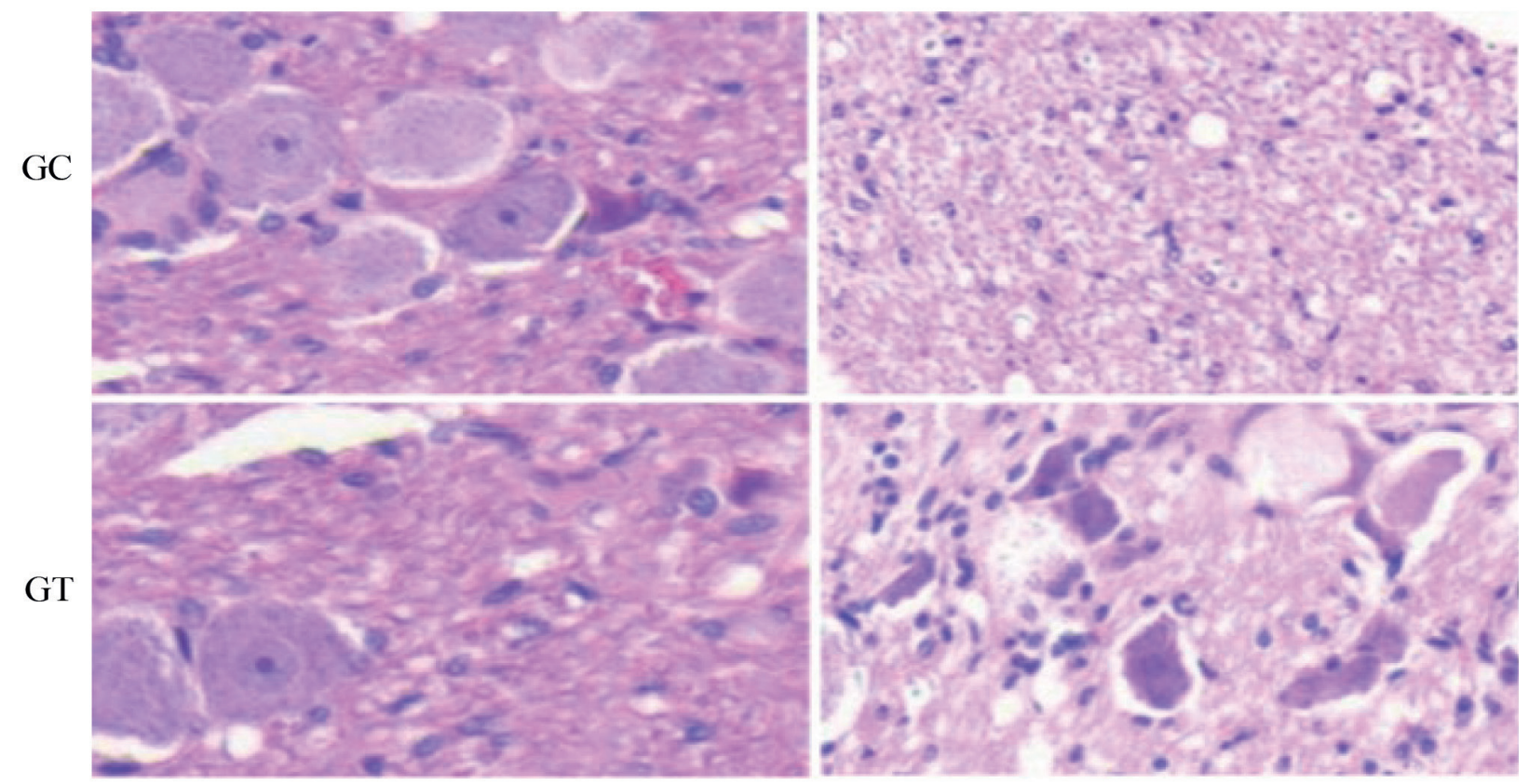

Fonte: Autoria própria

\section{DISCUSSÃO}

Os achados do presente estudo confirmam a hipótese de que a exposição à fumaça principal do tabaco é capaz de provocar alterações histopatológicas no nervo olfatório de ratas, bem como a eficácia do modelo de exposição à fumaça principal do cigarro. Esta eficácia pode ser evidenciada pelo aumento dos níveis de cotinina plasmática, em que o grupo GT apresentou maiores valores comparado ao grupo GC. Na literatura encontramos estudos experimentais (ROSA et al., 2017) que adotaram valores de 
referência de cotinina semelhante aos encontrados em humanos (CHIU; ISAAC; KUO, 2008) para caracterização da exposição como passiva $(2,1 \mathrm{a} 17,5 \mathrm{ng} / \mathrm{ml})$ ou ativa (> $17,5 \mathrm{ng} / \mathrm{ml}$ ). Portanto, de acordo com os níveis de cotinina plasmática a exposição dos animais do GT pode ser considerada passiva.

Sabe-se que as paredes dos vasos sanguíneos estão propensas a alterações em sua estrutura, tais como fragilidade, dilatação anormal e o aumento definitivo de sua espessura (GERZANICH et al., 2001). Estas alterações estão relacionadas aos efeitos tóxicos da fumaça principal do cigarro, decorrente de vários mecanismos. Tais como, a ativação e a dessensibilização de receptores presentes no endotélio vascular, diminuição endotelial da expressão da enzima óxido nítrico sintase e da indução de leucocitose na resposta pró-inflamatória vascular, esta mediada por espécies reativas de oxigênio, derivadas da queima dos cigarros como o peroxinitrito, superóxido, peróxido de hidrogênio e o radical hidroxila (ABBRUSCATO et al., 2002).

No presente estudo os efeitos tóxicos da fumaça do cigarro foi capaz de desencadear alterações no tecido olfatório e seus anexos. Assim, observa-se aumento da espessura da parede das arteríolas, concomitante ao processo de reparação cicatricial do nervo olfatório. As alterações vasculares encontradas são similares aos achados de outro estudo, no qual utilizou solução salina e tartarato de nicotina em um modelo com ratas (GERZANICH et al., 2001).

Levando em consideração que os agentes tóxicos podem induzir o comprometimento celular e funcional dos astrócitos, resultando em redução em sua quantidade em decorrência do acometimento do endotélio da barreira hematoencefálica, na literatura, encontra-se relatos que a nicotina e seu principal metabólito a cotinina podem estimular disfunções endoteliais e citotoxicidade de astrócitos acoplados a barreira hematoencefálica (ABBRUSCATO et al., 2002). Nosso modelo de estudo evidenciou que a fumaça principal do cigarro é lesiva em células gliais do nervo olfatório de ratas, mesmo em células resistentes a citotoxicidade como os astrócitos. Portanto, nossos achados estão em conformidade com a literatura que mostra em células cultivadas que a exposição à fumaça do cigarro promove citotoxicidade de astrócitos acoplados a barreira hematoencefálica.

As micróglias além de sua função fagocítica também são capazes de iniciar uma resposta rápida e específica a estímulos lesivos, participando da remodelação ou na inviabilidade do tecido nervoso acometido (BALPRICE; MATTHIAS; BROWN, 2002). No presente estudo inferimos que o aumento na quantidade de micróglias esteja relacionado a uma resposta inflamatória mediada pelos tóxicos da fumaça do cigarro. Já foi demonstrado que substâncias como peroxinitrito e superóxido demonstram um nível maior de toxicidade ao sistema nervoso, sendo capaz de promover lesões e aumentar a resposta microglial (GHOSH et al., 2009; ZELIKOFF et al., 2018).
A persistência da resposta microglial pode produzir um ambiente inflamatório crônico e resultar na deposição de matriz extracelular como colágeno levando à formação de uma cicatriz fibrótica (SILVER; MILLER, 2004).

No sistema nervoso central a matriz extracelular abrange o espaço entre neurônios e células gliais, porém seus componentes são diferentes da matriz dos demais tecidos do corpo, sendo que o colágeno por exemplo, se restringe as meninges, vasos sanguíneos e barreira hematoencefálica (BURNSIDE; BRADBURY, 2014). No caso de lesões no sistema nervoso central as células gliais são a principal fonte de deposição de matriz extracelular como forma de reparo (SODERBLOM et al., 2013).

A exposição aos componentes tóxicos da fumaça do cigarro interfere diretamente na deposição de matriz extracelular em vários tecidos do corpo, no entanto, não se conhece ainda qual seria a substância diretamente envolvida no aumento dessa matriz. Sabe-se que em tecido gengival de ratas a mistura de componentes presentes na fumaça do cigarro promove a diferenciação de fibroblastos e afeta respostas celulares envolvidas no processo de cicatrização (FERREIRA et al., 2020)

Células gliais depositam matriz extracelular no tecido nervoso com o objetivo de estabelecer uma cicatriz glial. Fibroblastos de origem perivascular podem estar presentes no local depositando colágeno e auxiliando na construção de uma cicatriz fibrótica (SILVER; MILLER, 2004; SODERBLOM et al., 2013). Dessa forma, a formação de uma cicatriz por depósito de matriz extracelular pode explicar o aumento do percentual do colágeno total no GT, em nosso estudo. A formação dessa cicatriz é fundamental para restabelecer a barreira hematoencefálica, proteger o tecido nervoso danificado e prevenir uma resposta inflamatória em proporções maiores (SILVER; MILLER, 2004).

\section{CONCLUSÃO}

Em síntese, nossos resultados apontam que a exposição à fumaça principal do cigarro é capaz de propiciar alterações vasculares e morfológicas das células gliais do nervo olfatório. Até onde sabemos, esses achados no nervo olfatório não foram relatados anteriormente, mas exige mais investigações básicas e estudos clínicos. No entanto, estes achados são fortes o suficiente para servir como alerta a toda população e às autoridades de saúde, o que se refere as leis antifumo, principalmente em ambientes fechados.

Contudo, a exposição à fumaça do cigarro em ratas afetou negativamente a morfologia das células gliais e dos vasos do nervo olfatório, sugerindo perda sensorial olfativa. Tais eventos parecem estar relacionados à resposta inflamatória e cicatricial frente aos agentes tóxicos presente na fumaça do cigarro.

\section{LIMITAÇÕES DO ESTUDO}

Como limitações do presente estudo destacamos a diferença entre a exposição a fumaça do tabaco dos ani- 
mais incluídos nesse estudo e a exposição dos humanos diariamente, sendo eles fumantes ativos ou passivos.

\section{AGRADECIMENTOS}

Agradecemos o apoio fornecido pelo Conselho Nacional de Desenvolvimento Científico e Tecnológico (CNPq), Coordenação para o Melhoramento do Pessoal de Educação Superior (CAPES), Fundação de Pesquisa do Estado de Minas Gerais (FAPEMIG) e Fundação de Educação e Pesquisa de Uberaba (FUNEPU).

\section{REFERÊNCIAS}

ABBRUSCATO, T. J. et al. Nicotine and cotinine modulate cerebral microvascular permeability and protein expression of ZO 1 through nicotinic acetylcholine receptors expressed on brain endothelial cells. J. Pharm. Sci., Washington, v. 91, n. 12, p. 2525-2538, Dec. 2002.

BALPRICE, A.; MATTHIAS, A.; BROWN, G. C. Stimulation of the NADPH oxidase in activated rat microglia removes nitric oxide but induces peroxynitrite production. J. Neurochem., New York, v. 80, n. 1, p. 7380, Jan. 2002

BURNSIDE, E. R.; BRADBURY, E. J. Review: manipulating the extracellular matrix and its role in brain and spinal cord plasticity and repair. Neuropathol. Appl. Neurobiol., Aachen, v. 40, n. 1, p. 26-59, 20 Jan. 2014.

CHIU, H. T.; ISAAC, W.U. H. D.; KUO, H. W. The relationship between self reported tobacco exposure and cotinines in urine and blood for pregnant women. Sci. Total. Environ., Amsterdam, v. 1-2, n. 406, p. 331-336, 15 Nov. 2008.

DE CASTRO, F. Wiring Olfaction: The Cellular and Molecular Mechanisms that Guide the Development of Synaptic Connections from the Nose to the Cortex. Front. Neurol., Lausanne, v.3, p. 52-52, 2009.

FERREIRA, F. J. P. A. et al. Periodontal disease and its relation to the inhalation of cigarette smoke. Acta. Sci., Anatomical., Rio de Janeiro, v. 1, n. supl. 1, p. 38-39, June 2020.

FRIED, N. D.; GARDNER, J. D. Heat-not-burn tobacco products: an emerging threat to cardiovascular health. Am. J. Physiol. Heart Circ. Physiol., Bethesda v. 319, n. 6, p. H1234-h1239, Dec. 2020.

GENTNER, N. J.; WEBER, L. P. Secondhand tobacco smoke, arterial stiffness, and altered circadian blood pressure patterns are associated with lung inflammation and oxidative stress in rats. Am. J. Physiol. Heart., Rockville, v. 302, n. 3, p. 818-825, Feb. 2012.

GERZANICH, V. et al. Chronic nicotine alters NO signaling of Ca (2+) channels in cerebral arterioles. Circ. Res., Dallas, v. 82, n. 3, p. 359-365. Feb. 2001.

GHOSH, D. et al. Tobacco carcinogen induces microglial activation and subsequent neuronal damage. J. Neurochem., Oxford, v. 110, n. 3, p. 1070-1081, Aug. 2009.

MELLO, P. R. B.; OKAY, T. S; BOTELHO, C. Efeitos da exposição à fumaça do cigarro sobre a produção láctea e o crescimento de filhotes de ratas. J. Pediatr., Rio de Janeiro, v. 83, n. 3, p. 267-273, jun. 2007.

ROSA, R. C. et al. O fumo passivo do tabaco afeta negativamente os ossos de ratos imaturos, Clinics., São Paulo, v. 72, n. 12, p. 785-789, dez. 2017.

SAHIN, E.; ORTUG, G.; ORTUG, A. Does cigarette smoke exposure lead to histopathological alterations in the olfactory epithelium? An electron microscopic study on a rat model, Ultrastruct Pathol., Oslo, v. 42, n. 5, p. 440-447, Sept./Oct. 2018.

SILVER, J.; MILLER, J. H. Regeneration beyond the glial scar, Nat, Rev. Neurosci, Londres, v. 5 n. 2 p. 146-156. Feb. 2004.

SODERBLOM, C. et al. Perivascular fibroblasts form the fibrotic scar after contusive spinal cord injury, J. Neurosci., New Haven, v. 33, n. 34, p. 13882-13887. Aug. 2020.

VARDAVAS, C. I.; NIKITARA, K. COVID-19 and smoking: a systematic review of the evidence. Tob Induc. Dis., Essen, v. 18, p. 20, 2020.

WORLD HEALTH ORGANIZATION (WHO). Report on the Global Tobacco Epidemic, 2017: Monitoring Tobacco Use and Prevention Policies. Geneva, Switzerland: World Health Organization, 2017.

ZELIKOFF, J. T. et al. M. Microglia Activation and Gene Expression Alteration of Neurotrophins in the Hippocampus Following Early-Life Exposure to E-Cigarette Aerosols in a Murine Model. Toxicol. Sci. Oxford, v. 162 , n. 1, p. 276-286, 2018.

Submetido em: $17 / 08 / 2020$

Aceito em: 15/03/2021 